\title{
Erratum to: Laboratory Study of the Effect of Sills on Radial Gate Discharge Coefficient
}

\author{
Farzin Salmasi*, Meysam Nouri**, and John Abraham***
}

Received June 3, 2018/Revised 1st: September 15, 2018, 2nd: October 29, 2018/Accepted January 5, 2019/Published Online February 7, 2019

Erratum to: KSCE Journal of Civil Engineering (2018)23(5): 2117-2125

DOI 10.1007/s12205-019-1114-y

This erratum is published to notify a correction in the author's name. Please take note that changes have been made to the second author, Meysam Nouri. See the corrected version below:

\section{Errata:}

The original version of this article:

Farzin Salmasi*, Mysam Nouri**, and John Abraham***

\section{Was altered as:}

Farzin Salmasi*, Meysam Nouri**, and John Abraham***

The original article has been corrected.

*Associate Professor, Dept. of Water Engineering, University of Tabriz, Tabriz, Iran (Corresponding Author, E-mail: Salmasi@tabrizu.ac.ir)

**M.Sc. Student, Dept. of Water Engineering, University of Tabriz, Tabriz-Iran (E-mail: meysamnouri71@gmail.com)

***Professor, School of Engineering, University of St. Thomas, St. Paul, MN 55105, USA (E-mail: jpabraham@stthomas.edu) 